\title{
Preparation of self-flocculated solid lipid nanoparticles
}

\author{
Ahmed GARDOUH ${ }^{1}$ * (D), El-Sayed KHAFAGY ${ }^{1}$ (D), Mohamed ELKADY 2 (D) \\ 1 Department of Pharmaceutics and Industrial Pharmacy, Faculty of Pharmacy, Suez Canal University, 415-22, Ismailia, \\ Egypt. \\ 2 Department of Organic Chemistry, Faculty of science, Ain Shams University, Cairo, Egypt. \\ * Corresponding author. E-mail: ahmed_mahmoud@pharm.suez.edu.eg (A.G.); Tel.+20-101-379 0828.
}

Received: 03 February 2019 / Revised: 28 March 2019 / Accepted: 20 April 2019

\begin{abstract}
The objective of this study was to verify the effect of certain new biocompatible additive on the stability and feasibility of the SLN using Glyceryl monostearate as lipid matrix. Cationic Starch, which is newly modified in organic chemistry laboratories, used with different ratios to show the effect on zeta potential of formulated nanoparticles using Triamcinolone acetonide as a model drug. Method of High shear homogenization was used for preparation of SLN utilizing a rotor-stator homogenizer. It was found that particle diameter of formulated nanoparticles shifted from nanosized to micronized with increase of amount of cationic starch used ( 2.5 to $10 \% \mathrm{w} / \mathrm{w})$, while the zeta potential reduced although showing high negative values $(-36$ to $-27 \mathrm{mV})$, indicating stability. The loading capacity and encapsulation efficiency of produced nanoparticles were reduced with increase of amount of cationic starch used. The influence of cationic starch on drug release from prepared formulae was studied using dialysis bag technique. Fourier Transformation Infrared Spectroscopy (FTIR) showed the absence of new bands for loaded solid lipid nanoparticles indicating no interaction between drug and cationic starch. Electron microscope of scanning technique indicated sphere form of prepared solid lipid nanoparticles with smooth surface. It was concluded that retardation of in vitro release and effect on simulated in vivo permeation through human skin were affected by using different concentrations of cationic starch as excipient that meantime, be used to reduce zeta potential and act as self-flocculating agent during formulation.
\end{abstract}

KEYWORDS: Solid lipid nanoparticles; cationic starch; triamcinolone acetonide; zeta potential; high shear homogenization.

\section{INTRODUCTION}

Flocculation processes can bring the smaller colloidal particles together to form larger flocks, which may cause significant changes in the colloidal stability and facilitate the removal of suspended solids and colloids [1]. However, the negative health and environmental issue of inorganic and synthetic polymer flocculants has been extensively reported $[2,3]$ recently numerous research articles have focused on the use of natural polysaccharides or their derivatives as replacements for conventional flocculants, which present considerable advantages including abundance, renewability, Eco-friendliness and cost effectiveness [4]. Chemically modified starches are commonly prepared by treating native starch granules with reagents that can react with hydroxyl groups on starch molecules. one of the chemically modified starches, cationic starches that possess positively charged groups such as amino, imino, ammonium and phosphonium, and are widely used for water purification and non-food products (e.g. cosmetics and topical products) [5]. cationic starches are generally synthesized by reaction of native starch with cationic reacting reagents such as epichlorohydrine with triethanolamine. Cationic starch derivatives are effective flocculants for negatively charged organic and inorganic colloidal particles over a wide range of $\mathrm{pH}$ [6-8]. Most of cationic starches are present in non-granular forms due to the use of excessive sodium hydroxide for purpose to enhance their degree of substitution [9]. However, limited information is available on physicochemical properties of granular- type cationic starch.

Solid Lipid Nanoparticles consist of drug trapped in biocompatible lipid core with surfactant on the outer shell, considered to be a good alternative to polymeric systems [10] in terms of lower toxicity [11]. Thus, the

How to cite this article: Gardouh A, Khafagy E, Elkady M. Preparation of self -flocculated solid lipid nanoparticles. J Res Pharm. $2019 ; 23(4)$ : 652-661. 
objective of this study was to synthesize cationic starch derivative originated from corn starch. The synthesized cationic starch will be used as an excipient during formulation of solid lipid nanoparticles to verify efficiency of this excipient on loading capacity, encapsulation efficiency, in- vitro dug release, and simulated in vivo permeation.

\section{RESULTS AND DISCUSSION}

\subsection{Effect of cationic starch on particle size and zeta potential of formulated solid lipid nanoparticles}

Cationic starch that was synthesized according to Kavaliauskaite et al. [12] and added during formulation of solid lipid nanoparticles of triamcinolone acetonide to study the effect of it on particle size and zeta potential. The results showed that all formulae prepared according to Table 1 have particle sizes within nanorange when measured by laser diffraction technique, except formula F4 with size of $1434.67 \pm 27.1$. The effect of cationic starch concentration increased from $2.5 \% \mathrm{w} / \mathrm{w}$ in formula F1 to formula F4 showed increase in particle size from $449.67 \pm 10.5$ to $1434.67 \pm 27.1$ (nm), while the particle size of model solid lipid nanoparticles was $275.67 \pm 5.13$. These results agreed with that of Almeida et al. [20] who stated that solid lipid nanoparticles are appropriate to incorporate lipophilic drugs that are dissolved in melted lipid. For polydispersity index, all results showed values less than one indicating homogeneity that may be due to high surfactant concentrations that effectively stabilize the particles created by forming a steric barrier on the particle surface, thereby protecting the particles from coagulation even in presence of minor concentration of cationic starch that may reduce negative charge on surface of particles [21-23]. Cationic starch as an additive cause reduction of Zeta potential indicated reduction of their surface negative charge from -40.41 to about $-27 \mathrm{mV}$, that may be due to partial neutralization of negative charge on surface of prepared solid lipid nanoparticles [24].

Table 1. Composition of prepared formulae.

\begin{tabular}{cccc}
\hline Formula code & Particule size \pm S.D $(\mathbf{n m})$ & $\begin{array}{c}\text { Zeta potential } \\
(\mathbf{m V})\end{array}$ & $\begin{array}{c}\text { Polydispersity index } \\
(\mathbf{P} . I .)\end{array}$ \\
\hline TA-SLN & $275.67 \pm 5.13$ & -40.41 & 0.259 \\
F1 & $449.67 \pm 10.5$ & -36.6 & 0.29 \\
F2 & $655.34 \pm 12.7$ & -35.3 & 0.36 \\
F3 & $735.12 \pm 12.2$ & -29.3 & 0.57 \\
F4 & $1434.67 \pm 27.1$ & -27.14 & 0.895 \\
\hline
\end{tabular}

\subsection{Scanning electron microscopy (SEM)}

The formulated solid lipid nanoparticles were scanned using scanning electron microscope to evaluate surface of them. Figure 1 showed illustrated scans of formulated solid lipid nanoparticles, from these scans, all solid lipid nanoparticles are spherical in shape with smooth surfaces.

\subsection{Effect of cationic starch on encapsulation efficiency, loading capacity and yield percentage of solid lipid nanoparticles}

The results in figure 2 of using Cationic starch as an additive showed enhanced encapsulation efficiency of model drug inside the prepared solid lipid nanoparticles, above $75 \%$ in all formulation relative to solid lipid nanoparticles without it, which may be due to higher lipid to drug ratio (5:1), also agreed with Kim et al. [24] who prepared verapamil nanoparticles with loading $>75 \%$ for all formulations with lipid drug ratio (5:1 and 10:1). Higher HLB values beside the hydrophilic nature of cationic starch may enhance loading and encapsulation efficiency depending on reduction of interfacial tension and enhancement of solubilization of model drugs [25].

\subsection{Effect of cationic starch on in vitro drug release from solid lipid nanoparticles}

Cationic starch resulted from chemical synthesis, which is originally dispersed in water and increases viscosity, beside glycerol, which is used in formulation by about $50 \%$ of total formula. Upon comparing in vitro drug release, using membrane technique, it was found that increasing concentration of cationic starch from $2.5 \%$ 
in formula $\mathrm{F} 1$ to $10 \%$ in formula $\mathrm{F} 4$, increased size of particles with reduction of available surface area for release, moreover, the consistency converted from liquid to semisolid one, leading to delayed release pattern as seen in figure 3. The results were in agreement with Bisrat et al. and Gardouh et al. who found that viscosity of glycerol affected the rate of dissolution and diffusion of griseofulvin that compatible with our results $[13,26]$.
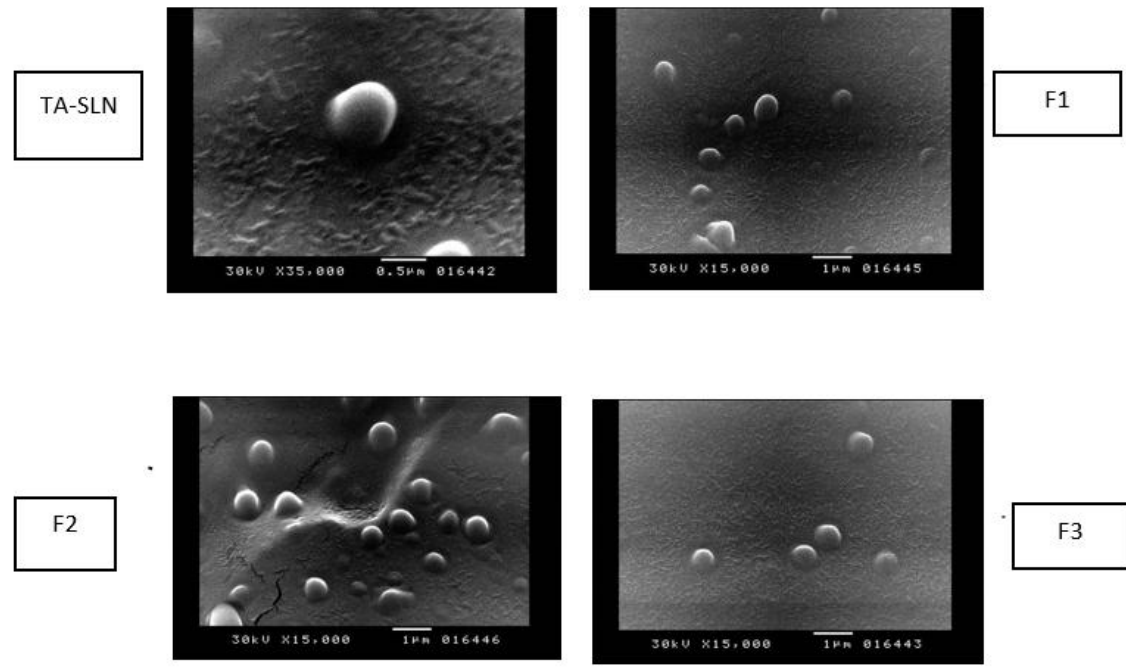

$$
\text { F3 }
$$

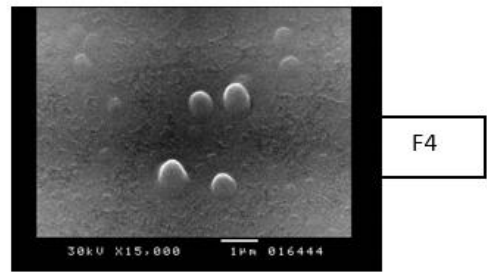

Figure 1. SEM micrographs of SLNs prepared using cationic starch as excipient, (magnification of $1 \mu \mathrm{m}$ indicates that size is in nanorange.

\subsection{Fourier transformation infrared spectroscopy}

The FTIR spectrum that characterize bands from the data of TA included the $\mathrm{OH}$ group in the range 3650$3200 \mathrm{~cm}^{-1}, \mathrm{C}-\mathrm{H}$ stretching in the range of $3000 \mathrm{~cm}^{-1}$ and $2900 \mathrm{~cm}^{-1}, \mathrm{C}=\mathrm{O}$ in $1775-1650 \mathrm{~cm}^{-1}, \mathrm{C}=\mathrm{C}$ in $1690-1635 \mathrm{~cm}^{-1}$, and $\mathrm{C}-\mathrm{O}-\mathrm{C}$ in $1310-1000 \mathrm{~cm}^{-1}$ [27]. The absence of new bands for TA-SLNs gave indication that there was no chemical interaction between the drug and the lipid, meant that drug only dissolved in the lipid matrix. Similar results were documented by Da Silva-Junior et al. [28] for triamcinolone loaded formulations. The peaks of cationic starch showed the same absorption bands of native starch indicating that backbone of anhydrous glucose units of the starch is not destroyed in the preparation process that appeared at 1158.3 and $929.1 \mathrm{~cm}-1$ are attributed to the alpha 1, 1 glycoside linkage bond (C-O-C) stretching vibration of the anhydrous glucose units. The bands at 1082.9 and $859.4 \mathrm{~cm}$-1are assigned to the $\mathrm{C}-\mathrm{O}-\mathrm{C}$ stretching vibrations in the ring. The band at $1017.2 \mathrm{~cm}-1$ is the characteristic absorption of the $\mathrm{C}-\mathrm{OH}$ stretch. The band at $2930.4 \mathrm{~cm}-1$ is the $\mathrm{CH} 2$ stretching vibration. The band a characteristic peak 3369.7 for $\mathrm{OH}$ group is strong indicating cationization. New peaks observed at 680, 1370.9 and $1130.4 \mathrm{~cm}-1$ can be attributed to $\mathrm{N}+$ symmetrical the $\left(\mathrm{CH}_{3}\right)_{3} \mathrm{~N}+$ symmetric bending and $\mathrm{CN}$ stretching vibration, respectively, indicating that cationization reaction is occurred.

\subsection{Simulated in vivo permeation study}

Ansari et al. [29] studied the permeation of diclofenac sodium and erythromycin base through different biologic membranes and found that these membranes have hydrophilic pores and channels which permeate small to medium size molecules like solid lipid nanoparticles. 
Figure 5 showed that the amount released from commercially available formulation and permeated through skin more than that from loaded solid lipid nanoparticles. This can be explained as if drugs were released from solid lipid nanoparticles before skin permeation; the figures would show higher release from solid lipid nanoparticles. But, while getting transported across the skin, SLN then probably expel drugs from SLN matrix as a consequence of polymorphic transitions occurring in the solid lipid. This phenomenon has been hypothesized in some investigations [30,31]. SLN have been shown to improve the dermal localization of several topical therapeutic agents [32-35]. This was one of the reasons to employ SLN approach for topical delivery of some drugs like tretinoin as its epidermal localization is highly desirable for enhancing the treatment of skin diseases such as psoriasis, acne, photo aging and epithelial skin cancer [36].

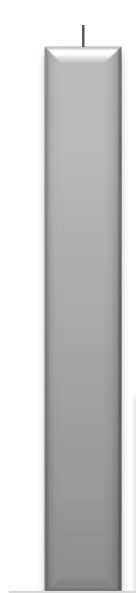

F4

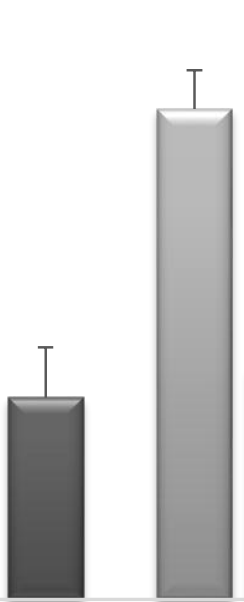

F3 $\boldsymbol{\nabla}$ yield percentage

๑encapsulation efficiency

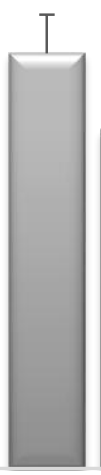

F2

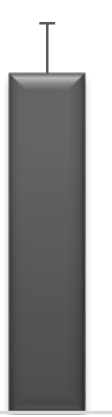

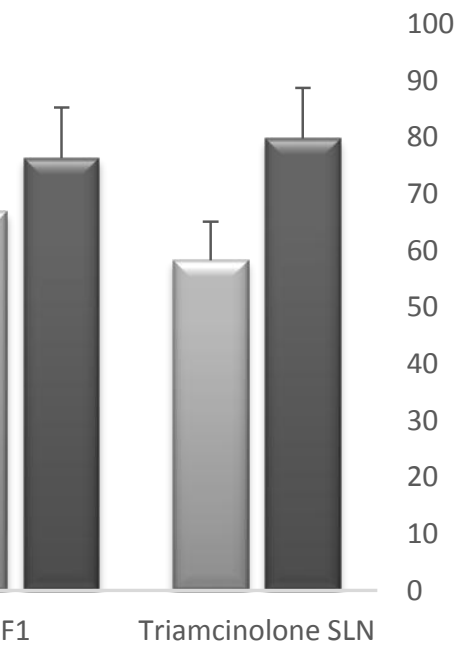

100

90

80

70

60

50

40

30

20

10

0

Figure 2. Effect of cationic starch on yield percentage and encapsulation efficiency of triamcinolone acetonide in prepared solid lipid nanoparticles. Each data point represents the mean $\pm S E, n=3$.

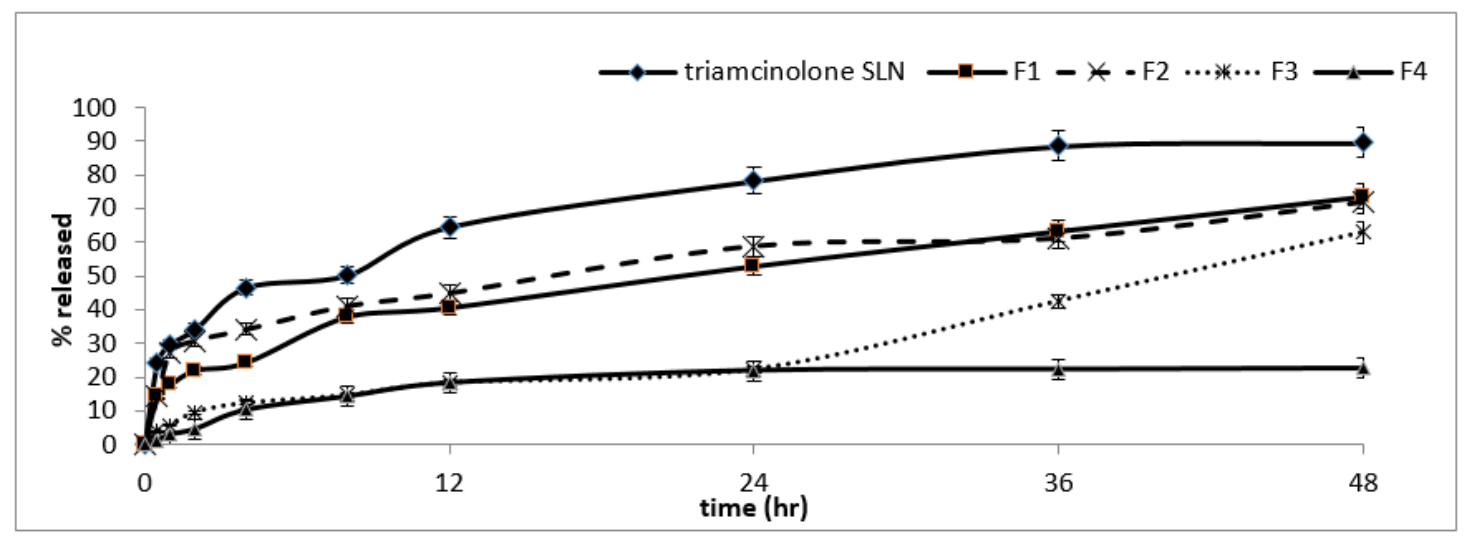

Figure 3. Effect of cationic starch on in vitro release of triamcinolone acetonide from prepared solid lipid nanoparticles. Each data point represents the mean $\pm S E, n=3$. 

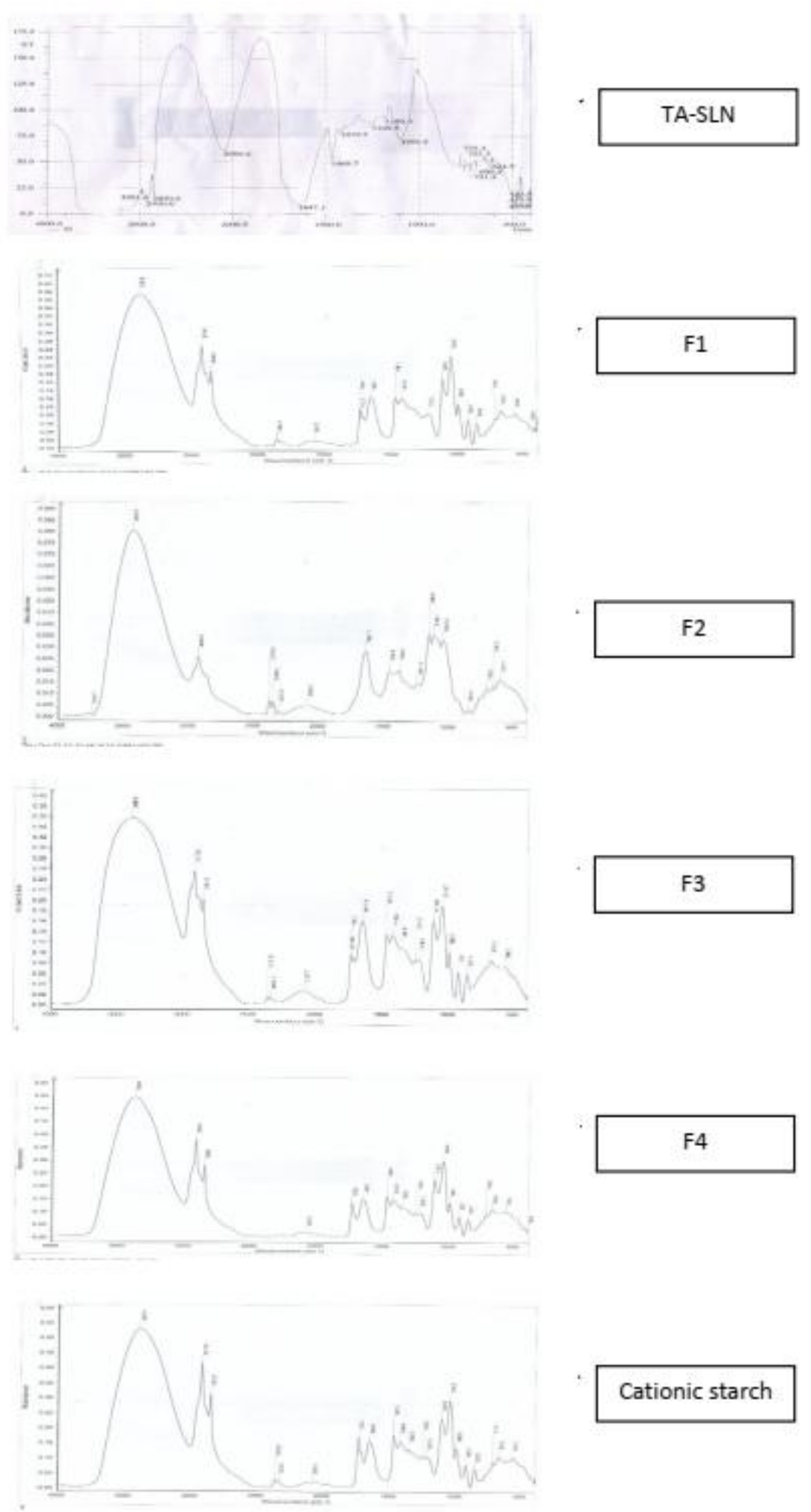

\section{Cationic starch}

Figure 4. FTIR spectra of TA-SLN and SLN formulae prepared using cationic starch as an excipient. 


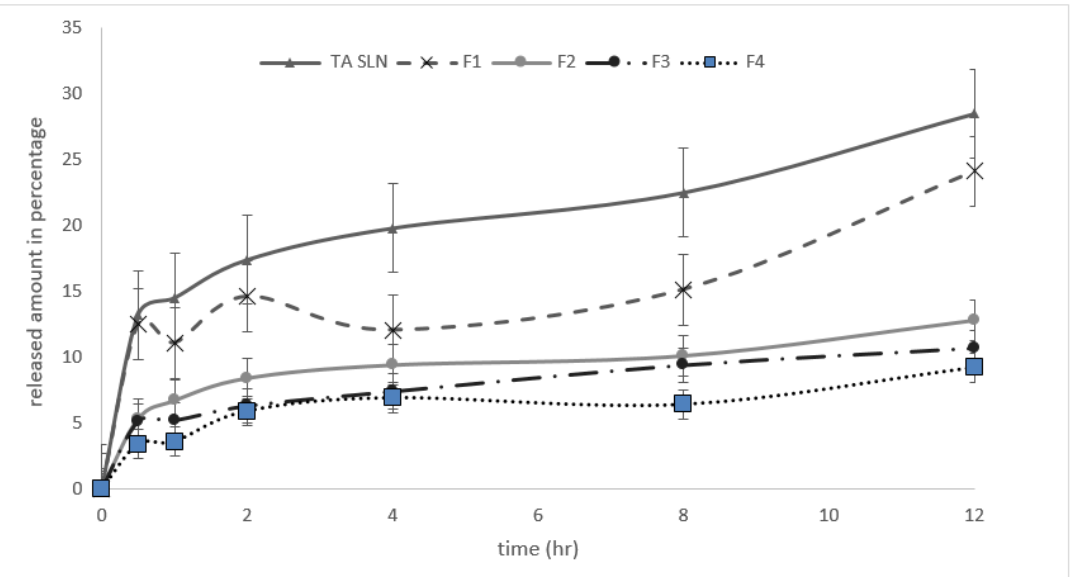

Figure 5. Simulated in vivo permeation profile of triamcinolone acetonide through human skin from the SLN prepared using cationic starch. Data expressed as mean $\pm S E, n=3$.

\section{CONCLUSION}

Particle size and other characterizations of Solid lipid nanoparticles prepared by high shear hot homogenization technique affected by addition of chemically synthesized cationic starch. Retardation of in vitro release and effect on simulated in vivo permeation through human skin were also affected by using different concentrations of cationic starch as excipient that meantime, be used to reduce zeta potential and act as selfflocculating agent during formulation.

\section{MATERIALS AND METHODS}

\subsection{Materials}

Egyptian corn starch as native starch obtained from local market in Egypt, epichlorohydrine ( Loba / chemi , India), triethanolamine free gift from ( El-Nasr pharmaceutical company, Cairo Egypt) Glyceryl monostearatetechnical self-emulsifying (BDH Chemicals Ltd Poole-England), Tween 80 (polysorbate 80), Tween 20 (polysorbate 20), ICI America (Wilmington, DE, USA), Lecithin (Spectrum Chemicals \& Laboratory Products, New Brunswick, $\mathrm{NJ}$ ), triamcinolone acetonide gift from (MUP pharmaceutical company, Abu sultan, Egypt), Dialysis tubing cellulose membrane (molecular weight cut-off 12,000 g/mole) sigma-Aldrich Chemical Company, St. Louis, USA, and all other chemicals were of reagent grade and used as delivered.

\subsection{Methods}

\subsubsection{Synthesis of cationic starch}

One milliliter of aqueous solution of sodium hydroxide ( 0.5 molar) was added to the reaction vessel containing 5 grams of native corn starch. The mixture was then refluxed for half an hour. To the previous mixture, epichlorohydrin was added with molar ratio 2:1 mixture and refluxed for one hour. To the whole mixture, 1:2 molar ratio triethanolamine was added drop-wise and refluxed for an hour, cooled to the room temperature then dissolved in $50 \%$ ethanol and neutralized by hydrochloric acid to $\mathrm{pH} 7$, the product finally filtered out and washed by $50 \%$ ethanol solution, as illustrated in Figure (6) [12].

\subsubsection{Preparation of solid lipid nanoparticles (SLN) loaded with Triamcinolone acetonide}

The method was illustrated in details according to Gardouh et al. [13]. Briefly, triamcinolone acetonide (TA) was dispersed in melted lipid $\left(60-70^{\circ} \mathrm{C}\right)$, then the mixture of Tween 80, lecithin, Glycerol and cationic starch were dispersed in water and heated to the same temperature, by high-speed stirring, using an Ultra-Turrax 
homogenizer (Ultra- Turrax T - 25, IKA, Germany) at 12, $000 \mathrm{rpm}$ for 10 minutes, with 30 seconds intervals every two minutes. The resulting dispersion was then cooled and each sample was diluted with water before measurement and particle size was measured using dynamic laser light scattering apparatus at $25^{\circ} \mathrm{C}$. (Mastersizer 2000 vers. 5.54, hydro 2000 S, Malvern instruments Ltd., Malvern, Worcs, UK). Each measurement was performed in triplicate and the particles average diameter and polydispersity index (PI) were determined [14]. Table 2 summarizes the ratios of formulae.

Table 2. Composition of prepared formulae.

\begin{tabular}{ccccccc}
\hline $\begin{array}{c}\text { Formula } \\
\text { code }\end{array}$ & $\begin{array}{c}\text { Drug } \\
\mathbf{\%} \\
\mathbf{W} / \mathbf{W}\end{array}$ & $\begin{array}{c}\text { GMS } \\
\mathbf{\%} \mathbf{w} / \mathbf{w}\end{array}$ & $\begin{array}{c}\text { Tween } \mathbf{8 0} \\
\mathbf{\%} \mathbf{w} / \mathbf{w}\end{array}$ & $\begin{array}{c}\text { lecithin } \\
\mathbf{\%} \mathbf{w} / \mathbf{w}\end{array}$ & $\begin{array}{c}\text { Glycerol } \\
\mathbf{\% w} / \mathbf{w}\end{array}$ & $\begin{array}{c}\text { Cationic } \\
\text { starch } \% \mathbf{w} / \mathbf{w}\end{array}$ \\
\hline TA SLN & 1 & 10.0 & 5.0 & 1.0 & 50.0 & 0.0 \\
F1 & 1 & 10.0 & 5.0 & 1.0 & 50.0 & 2.5 \\
F2 & 1 & 10.0 & 5.0 & 1.0 & 50.0 & 5.0 \\
F3 & 1 & 10.0 & 5.0 & 1.0 & 50.0 & 7.5 \\
F4 & 1 & 10.0 & 5.0 & 1.0 & 50.0 & 10.0 \\
\hline
\end{tabular}

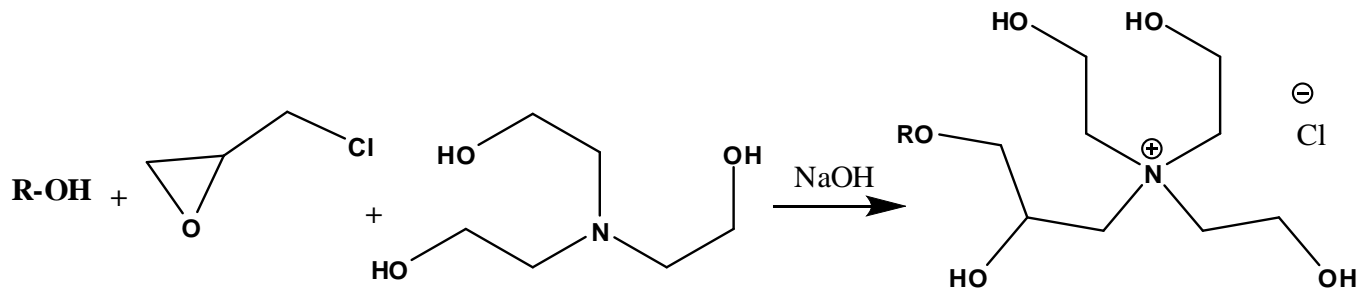

Figure 6. Reaction of cationic starch synthesis.

\subsubsection{Measurement of zeta potential}

The zeta potentials of the formulated SLN were determined after preparation using Zetasizer (Nano- ZS, Malvern Instruments England). Each sample was diluted with bi-distilled water and the electrophoretic mobility determined at $25^{\circ} \mathrm{C}$ and the obtained electrophoretic mobility values were used to calculate the zeta potentials using the software DTS Version 4.1 (Malvern, England) [15].

\subsubsection{Loading capacity and yield of solid lipid nanoparticles}

The loading capacity (L.C) gives an indication of the percentage amount of drug entrapped in solid lipid nanoparticles [16]:

$$
\text { L. C. }=\text { Total amount of drug }- \text { amount of unbound drug/nanoparticles weight } \%
$$

While yield of solid lipid nanoparticles was calculated by weighing centrifuged samples of isolated solid lipid nanoparticles and referring them to the initial amount of solid lipid nanoparticles components according to the following equation: [16]

$$
\text { Yield percentage }=\text { SLNs weight } / \text { Total initial solids weight } \%
$$

\subsubsection{Encapsulation efficiency}

Drug entrapment efficiency was determined by ultracentrifugation [17]. The drug entrapment efficiency was calculated from the ratio of the drug amount incorporated into SLNs to the total amount of drug. Ultracentrifugation was carried out using ultracentrifuge (Eppendorf centrifuge 5417 C, Netheler- Hinz- Gmbh), 
About $1 \mathrm{gm}$ of SLNs dispersion containing Triamcinolone acetonide was placed in the centrifuge tube, and samples were centrifuged at 14,000 rpm for $15 \mathrm{~min}$. The amount of Triamcinolone acetonide in the supernatant was estimated spectrophotometrically at $\lambda_{\max } 250 \mathrm{~nm}$ [18].

$$
\text { E.E. }=\text { Total amount of drug }- \text { amount of unbound drug } / \text { Total amount of drug } \%
$$

\subsubsection{Scanning electron microscopy (SEM)}

For scanning electron microscopy (SEM), dried solid lipid nanoparticles loaded with model drugs were fixed on a brass stub using double-sided adhesive tape and then made electrically conductive by coating with a thin layer of gold for 30 seconds using JEOL fine coat (JFC-1100F ion sputtering device) and scanned using JEOL (JSM-S.M 5300) using software (ORION 6.60.4).

\subsubsection{Fourier transformation infrared spectroscopy (FTIR)}

FT-IR spectra of the pure drug, cationic starch, and Triamcinolone acetonide loaded dried solid lipid nanoparticles were recorded using $\mathrm{KBr}$ disc technique. The samples were mixed with anhydrous $\mathrm{KBr}$ (IR grade) in the ratio of 100: 1 , then compressed into thin disk-shaped pellets, and then scanned over a wave number range 4000- $500 \mathrm{~cm}^{-1}$. Measurements were carried out using Shimadzu 435 U-O4 IR spectrometer, (Japan) (at the MicroAnalytical Center of Faculty of Science, Cairo University, Egypt).

\subsubsection{Effect of cationic starch on in- vitro drug release studies}

These studies were completed using horizontal water bath shaker (Clifton water bath, USA) that maintained at 60 cycles per minute and the dialysis bag that could retain SLNs and allow the diffusion of free drug into dissolution media. The bags were soaked in distilled water for $12 \mathrm{~h}$ before use. The release medium was $10 \mathrm{ml}$ phosphate buffer ( $\mathrm{pH}$ 5.5). The temperature was set at $32 \pm 0.5^{\circ} \mathrm{C}$. A $1 \mathrm{gm}$ sample of the drug loaded SLNs was instilled in a dialysis bag held with two clamps at each end. At known time intervals $(0.5,1,2,4,8,12,24,36$, and $48 \mathrm{~h}$ ) the complete media were withdrawn and replaced by equal volumes of fresh buffer to maintain sink condition. The samples filtered and assayed for Triamcinolone acetonide spectrophotometrically at $\lambda_{\max } 250 \mathrm{~nm}$ with Shimadzu double beam UV- visible spectrophotometer model UV-1601PC connected to a ProMax computer fitted with UPVC personal spectroscopy software version 3.7 (Shimadzu Corporation, Kyoto, Japan). The experiments were carried out as triplicate for each release study and the mean values were calculated [19].

\subsubsection{Statistical analysis}

All data were expressed as mean \pm SEM. Data were analyzed by using the program SPSS 16.0 (SPSS Inc., Chicago, IL, USA) with help of one-way analysis of variance (ANOVA) test followed by post hoc multiple comparisons and (LSD) least significant difference formulae be significant at $P<0.05$.

\subsubsection{Simulated in vitro release studies using Franz cells}

Effect of cationic starch on permeation of triamcinolone acetonide from prepared solid lipid nanoparticles was studied. Human cadaver skin (HCS) was taken from the abdominal region, after removing hair and subcutaneous fat tissue, punching out a disk of approximately $2.2-\mathrm{cm}^{2}$ area. The skin was hydrated for $24 \mathrm{~h}$ in the diffusion medium then mounted on the Franz diffusion cell (50-ml capacity with $2.5-\mathrm{cm}^{2}$ diffusion surface area). Phosphate buffer ( $\mathrm{pH}$ 5.5) served as receptor fluid stirred at $500 \mathrm{rpm}$ using magnetic stirrer. A small quantity of the formulae (equivalent to $50 \mathrm{mg}$ model drug) was applied to the skin surface and temperature of diffusion cell was maintained at $32^{\circ} \mathrm{C}$. Serial sampling $(1 \mathrm{ml})$ was performed at specified time intervals $(0.5,1.0,2.0,4.0,8.0,12.0$ hrs.). By removing the contents of the receptor compartment and replacing it with the fresh medium. The samples were analyzed and mean cumulative amount diffused $Q \%$ at each sampling time points was calculated [20]. 
Author contributions: Concept - A.G., M.E; Design - A.G., E.K., M.E; Supervision - M.E; Materials A.G; Data Collection and Processing - A.G., E.K; Analysis and Interpretation -A. G, E.K., M.K; Literature Search - A.G., E.K., M.E; Writing - A.G; Critical Reviews - A.G., E.K., M.E.

Conflicts of interest statement: There is no conflict of interest in this study and publication.

\section{REFERENCES}

[1] Pal S, Sen G, Carmaker NC, Mal D, Singh RP. High performance flocculating agents based on cationic polysaccharides in relation to coal fine suspension. Carbohyd Polym. 2008; 74(3): 590-596. [CrossRef]

[2] Krentz D, Lohmann C, Schwarz S, Bratskaya S, Liebert T, Laube J, HeinzeT, Kulicke W. Properties and Flocculation Efficiency of Highly Cationized Starch Derivatives. Starch - Stärke. 2006; 58(3-4): 161-169. [CrossRef]

[3] You L, Lu F, Li D, Qiao Z, Yin Y. Preparation and flocculation properties of cationic starch/chitosan crosslinkingcopolymer. J Hazard Mater. 2009; 172 (1): 38-45. [CrossRef]

[4] Jiang X, Qi Y, Wang S, Tian X. New amphoteric flocculant containing beta-cyclodextrin, synthesis, characterization and decolorization properties. J Hazard Mater. 2010; 173(1-3): 298-304. [CrossRef]

[5] Chang Y, Choi H, Kim H, Lee H, Kim W, Kim D, Kim B, Baik M. Physicochemical properties of granular and non-granular cationic starches prepared under ultra-high pressure. Carbohyd Polym. 2014; 99:385-393. [CrossRef]

[6] Pal S, Mal D, Singh RP. Cationic starch: an effective flocculating agent. Carbohyd Polym. 2005; 59(4): 417-423. [CrossRef]

[7] Wei Y, Cheng F, Zheng H. Synthesis and flocculating properties of cationic starch derivatives. Carbohyd Polym. 2008; 74(3): 673-679. [CrossRef]

[8] Zhang B, Ni B, Lü S, Cui D, Liu M, Gong H, Han F. Synthesis and characterization of a novel potato starch derivative with cationic acetylcholine groups. Int J Biol Macromol. 2012; 50(3): 701-706. [CrossRef]

[9] Pi-xin W, Xiu-li W, Xue D, Xu K, Tan Y, Du X, Li W. Preparation and characterization of cationic corn starch with a high degree of substitution in dioxane-THF-water media. Carbohyd Res. 2009; 344(7): 851-855. [CrossRef]

[10] Raghavendra CM, Ramesh B, Vidhya R, Pradip P, Tejraj MA. Nano/microTechnologies for Delivering Macromolecular Therapeutics using Poly (d, l-lactide-coglycolide) and its Derivative. J Control Rel. 2008; 125:193-209. [CrossRef]

[11] Muller RH, Mader K, Gohla S. Solid lipid nanoparticles (SLN) for controlled drug delivery - a review of the state of the art. Eur J Pharm Biopharm. 2000; 50: 161-177. [CrossRef]

[12] Kavaliauskaite R, Klimaviciute R, Zemaitaitis A. Factors influencing production of cationic starches. Carbohyd Polym. 2008; 73(4,5): 665-675. [CrossRef]

[13] Gardouh A R, Gad S, Ghonaim H M, Ghorab M M. Design and Characterization of Glyceryl Monostearate Solid Lipid Nanoparticles Prepared by High Shear Homogenization. Br J Pharm Res. 2013; 3(3): 326-346.

[14] Mehnert W, Mader K. Solid lipid Nanoparticles production, characterization and applications. Adv Drug Deliv Reviews. 2001; 47: 165-196. [CrossRef]

[15] Attama AA, Muller- Goymann CC. Effect of beeswax modification on the lipid matrix and solid lipid nanoparticle crystallinity. Coll Surf A Physiochem Eng Aspects. 2008; 315: 189-195. [CrossRef]

[16] Abdelbary G, FahmyR H. Diazepam-Loaded Solid Lipid Nanoparticles: Design and Characterization. AAPS Pharm SciTech. 2009; 10(1): 211-219. [CrossRef]

[17] Bhalekar MR, Pokharkar V, Madgulkar A, Patil N, Patil N. Preparation and Evaluation of Miconazole Nitrate-Loaded Solid Lipid Nanoparticles for Topical Delivery. AAPS Pharm Sci Tech. 2009; 10(1): 289-296. [CrossRef]

[18] British pharmacopoeia. Commission office. British pharmacopoeia. The stationary Office, London; 2009. 
[19] Feng W, Jian Y, Yu S, Xing-Guo Z, Fu-De C, Yong-Zhong D, Hong Y, Fu-Qiang H. Studies on PEG-modified SLNs loading vinorelbine bitartrate (I): Preparation and evaluation in vitro. Int J Pharm. 2008; 359: 104-110. [CrossRef]

[20] Almeida AJ, Runge S, Muller RH. Peptide -loaded solid lipid Nanoparticles (SLN): influence of production parameters. Int J Pharm. 1997; 149: 255- 265. [CrossRef]

[21] Lim S, Kim C. Formulation parameters determining the physicochemical characteristics of solid lipid nanoparticles loaded with all-trans retinoic acid. Int J Pharm. 2002; 243: 135-146. [CrossRef]

[22] Harivardhan Reddy L, Murthy R S. Etoposide-loaded nanoparticles made from glyceride lipids: formulation, characterization, in vitro drug release, and stability evaluation. AAPS Pharm Sci Tech. 2005; 6(2): E58-E166. [CrossRef]

[23] Xiang L, Shu-fang N, Jun K, Ning L, Cheng-yi J, Wei-san P. A controlled-release ocular delivery system for ibuprofen based on nanostructured lipid carriers. Int J Pharm. 2008; 363: 177-182. [CrossRef]

[24] Kim BD, Na K, Choi HK. Preparation and characterization of solid lipid Nanoparticles (SLN) made of cacao butter and curdlan. Eur J Pharm Sci. 2005; 24: 199-205. [CrossRef]

[25] Ghorab MM, Abdel-salam HM, Abdel-Moaty MM. Solid lipid Nanoparticles-effect of lipid matrix and surfactant on their physical characteristics. Bull Pharm Sci, Assiut Uni. 2004; 27: 155-159.

[26] Bisrat M, Anderberg EK, Barnett M I, Nyström C. Physicochemical aspects of drug release. XV. Investigation of diffusional transport in dissolution of suspended, sparingly soluble drugs. Int J Pharm. 1992; 80(1-3): 191-201. [CrossRef]

[27] Pretsch E, Bühlmann P, Badertscher M. IR Spectroscopy. Structure Determination of Organic Compounds 2000; 267-320: Springer, Berlin Heidelberg.

[28] Da Silva-Junior AA, De Matos JR, Formariz TP, Rossanezi G, Scarpa MV, Do Egito EST, De Oliveira AG. Thermal behavior and stability of biodegradable spray-dried microparticles containing triamcinolone. Int J Pharm. 2009; 368: 45-55. [CrossRef]

[29] Ansari M, Kazemipour M, Aklamli M. The study of drug permeation through natural membranes. Int J Pharm. 2006; 327: 6-11. [CrossRef]

[30] Mei Z, Chen H, Weng T, Yang Y, Yang X. Solid lipid nanoparticles and microemulsion for topical delivery of triptolide. Eur J Pharm Biopharm. 2003; 56: 189-196. [CrossRef]

[31] Jain SK, Chourasia MK, Masuriha R, Soni V, Jain A, Jain NK, Gupta Y. Solid lipid nanoparticles bearing flurbiprofen for transdermal delivery. Drug Del. 2005; 12: 207-215. [CrossRef]

[32] Maia CS, MehnertW, Schaller M, Korting HC, Gysler A, Haberland A, Schafer-Korting M. Drug targeting by solid lipid nanoparticles for dermal use. J Drug Target. 2002; 10: 489-495. [CrossRef]

[33] Chen H, Chang X, Du D, Liu W, Liu J, Weng T, Yang Y, Xu H, Yang X. Podophyllotoxin-loaded solid lipid nanoparticles for epidermal targeting. J Control Rel. 2006; 110:296-306. [CrossRef]

[34] Lopes LB, Ferreira DA, Paula D, Garcia MJ, Thomazini JA, Fantini MA, Bentley MB. Reverse hexagonal phase Nano dispersion of monoolein and oleic acid for topical delivery of peptides: in vitro and in vivo skin penetration of Cyclosporin A. Pharm Res. 2006; 23: 1332-1342. [CrossRef]

[35] Liu J, Hu W, Chen H, Ni Q, Xu H, Yang X. Isotretinoin-loaded solid lipid nanoparticles with skin targeting for topical delivery. Int J Pharm. 2007; 328: 191-195. [CrossRef]

[36] Kumar AS, Abhijit AD, Medha DJ, Vandana BP. Solid lipid nanoparticles (SLN) of tretinoin: Potential in topical delivery. Int J Pharm. 2007; 345: 163-171. [CrossRef]

This is an open access article which is publicly available on our journal's website under Institutional Repository at http://dspace.marmara.edu.tr. 